\title{
Correction to: An LQP-Based Symmetric Alternating Direction Method of Multipliers with Larger Step Sizes
}

\author{
Zhong-Ming $\mathrm{Wu}^{1}$ (D) $\cdot \mathrm{Min} \mathrm{Li}^{2}$
}

(c) Operations Research Society of China, Periodicals Agency of Shanghai University, Science Press, and Springer-Verlag GmbH Germany, part of Springer Nature 2019, corrected publication 2019

\section{Correction to: Journal of the Operations Research Society of China https://doi.org/10.1007/s40305-019-00247-y}

The correct fund note for the original version is provided in this correction.

This research was supported by National Natural Science Foundation of China Grant 11771078, Natural Science Foundation of Jiangsu Province Grant BK20181258, Project of 333 of Jiangsu Province Grant BRA2018351 and Postgraduate Research and Practice Innovation Program of Jiangsu Province Grant KYCX18_0200.

The original article has been corrected.

The original article can be found online at https://doi.org/10.1007/s40305-019-00247-y.

$凶$ Zhong-Ming Wu

wuzm@seu.edu.cn

Min Li

limin@nju.edu.cn

1 School of Economics and Management, Southeast University, Nanjing 210096, China

2 School of Management and Engineering, Nanjing University, Nanjing 210093, China 